\title{
Medication Reconciliation: More than Just a Best Possible Medication History
}

\author{
Peter J Zed
}

$\mathrm{T}$ he Institute for Safe Medication Practices Canada (ISMP Canada) defines medication reconciliation as "a formal process in which healthcare providers work together with patients, families and care providers to ensure accurate and comprehensive medication information is communicated consistently across transitions of care." It is based on "a systematic and comprehensive review of all the medications a patient is taking . . . to ensure that medications being added, changed or discontinued are carefully evaluated. It is a component of medication management and will inform and enable prescribers to make the most appropriate prescribing decisions for the patient." ${ }^{1}$ Medication reconciliation has been endorsed by patient safety organizations and implemented in many institutions around the world to ensure accurate communication on admission, on transfer, and at discharge. It was introduced into the Accreditation Canada program as a Required Organizational Practice in 2005, so for the past decade our health care institutions have been evaluated on their ability to comply with these standards, and compliance has improved throughout the country over this period. ${ }^{2}$ Clearly, the medication reconciliation process has value, and few would debate that better communication about medications across the continuum of care can reduce medication-related adverse events and improve patient adherence with therapy. Improved communication about medications on transfer and at discharge may also decrease return visits to the emergency department and unplanned hospital readmissions, which together can significantly reduce the consumption of health care resources.

Acquisition of a best possible medication history (BPMH) on admission is a critical step in medication reconciliation. Although often performed by a pharmacy team member, it can be accurately performed by any member of the health care team, including a student. There is clear evidence that pharmacists and other health care providers can obtain accurate BPMHs for patients on admission to hospital, a step that leads to the identification of medication discrepancies. ${ }^{3}$ However, there remain challenges in completing the far more important task of utilizing the BPMH as part of medication management and pharmaceutical care. In other words, the $\mathrm{BPMH}$ is an important and necessary step, but it is the purposeful evaluation and resolution of the drug therapy problems (DTPs) identified that will do the

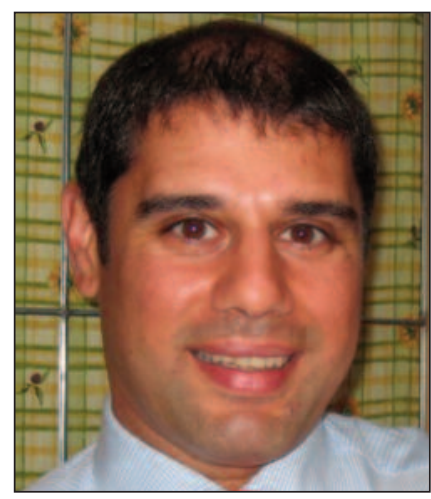
most to improve patients' health outcomes.

To date, resources for medication reconciliation have been focused on admission to health care facilities, with less attention paid to transfers within and discharges from these facilities. ${ }^{2}$ In particular, medication discrepancies at discharge are just as problematic as those identified on admission and are more likely to result in an adverse event if not identified and resolved. ${ }^{4}$ Adverse events occur in up to $25 \%$ of patients within 30 days of discharge from hospital, and half of these are preventable. ${ }^{5}$ One of the approaches to preventing these events is purposeful attention to medication reconciliation at discharge, with transfer of care and communication to community-based members of the health care team and better education for patients and their families. Of course, this process requires resources and efficient procedures, but it must become an integral component of patient care.

The medication reconciliation process must remain the cornerstone of pharmaceutical care provided to all patients throughout the continuum of their care. However, this process should not stop with acquisition of the BPMH on admission; instead, greater emphasis should be placed on the identification and resolution of all DTPs for every patient, with the BPMH being reviewed and updated throughout the trajectory of care. It is only through these critical steps, with optimization of each 
patient's pharmacotherapy regimen and appropriate monitoring on admission, transfer, and discharge, that we will have the greatest impact on reducing adverse events and reducing healthrelated utilization of resources in terms of visits to the emergency department and unplanned admissions to hospital. Obtaining an accurate BPMH on admission and then allowing DTPs to remain unresolved through subsequent transitions of care will benefit no one, least of all the patient. Let us all take the next step and ensure that medication reconciliation encompasses not just the acquisition of a BPMH on admission, but also the best possible care that we can provide, to ensure optimal pharmacotherapy and the improved health outcomes that we know will result.

\section{References}

1. Medication reconciliation (MedRec). Toronto (ON): ISMP Canada; (C20002015 [cited 2015 Jan 2). Available from: www.ismp-canada.org/medrec/

2. Accreditation Canada, Canadian Institute for Health Information, Canadian Patient Safety Institute, Institute for Safe Medication Practices Canada. Medication reconciliation in Canada: raising the bar. Progress to date and the course ahead. Ottawa (ON): Accreditation Canada; 2012.

3. Cornish PL, Knowles SR, Marchesano R, Tam V, Shadowitz S, Juurlink DN, et al. Unintended medication discrepancies at the time of hospital admission. Arch Intern Med. 2005;165(4):424-9.
4. Wong JD, Bajcar JM, Wong GG, Alibhai SM, Huh JH, Cest A, et al. Medication reconciliation at hospital discharge: evaluating discrepancies. Ann Pharmacother. 2008;42(10):1373-9.

5. Forster AJ, Clark HD, Menard A, Dupuis N, Chernish R, Chandok N, et al. Adverse events among medical patients after discharge from hospital. CMAJ. 2004;170(3):345-9. Erratum in: CMAJ. 2004;170(5):771.

Peter J Zed, BSC, BSC(Pharm), ACPR, PharmD, FCSHP, is Associate Professor and Associate Dean, Practice Innovation, Faculty of Pharmaceutical Sciences, and Associate Member, Department of Emergency Medicine, Faculty of Medicine, University of British Columbia, Vancouver, British Columbia. He is also an Associate Editor with the CJHP.

Competing interests: None declared.

\section{Address correspondence to:}

Dr Peter J Zed

Faculty of Pharmaceutical Sciences

University of British Columbia

2405 Wesbrook Mall

Vancouver BC V6T $1 Z 3$

e-mail : peter.zed@ubc.ca

\section{ON THE FRONT COVER}

\section{Barron Canyon by Skis Algonquin Park, Ontario}

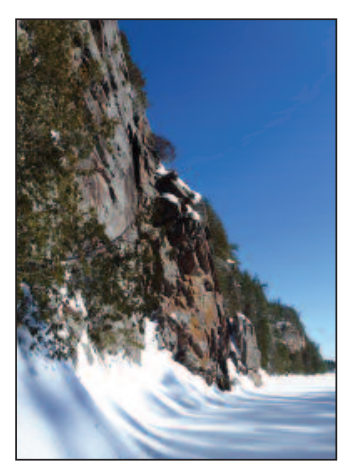

CSHP member Caroline Cheng (a hospital pharmacist at the Queensway-Carleton Hospital in Ottawa) describes this issue's cover photograph in her own words: "Algonquin Park's Barron Canyon is a popular canoe route and hiking destination in the spring, summer, and fall. However, this part of the park receives few visitors during the winter. This photo was taken with a Panasonic Lumix DMC-ZS10 camera during a back-country ski trip into the Barron Canyon. It was cold, but all of us wanted to linger in this magical vista of snow, rocks, and trees."

The CJHP would be pleased to consider photographs featuring Canadian scenery taken by CSHP members for use on the front cover of the journal. If you would like to submit a photograph, please send an electronic copy (minimum resolution $300 \mathrm{dpi}$ ) to cjhpedit@cshp.ca. 